TABLE VI. Effects of Tolbutamide on the Metabolism of CHS-Na in Rabbit Liver in Vitro

\begin{tabular}{|c|c|c|c|c|}
\hline \multirow{2}{*}{ Condition } & \multicolumn{4}{|c|}{$\%$ produced } \\
\hline & Cyclohexylamine & Cyclohexanone & Cyclohexanol & Total metabolites \\
\hline Alone & 0.0094 & 0.0072 & 0.0038 & 0.0204 \\
\hline $\begin{array}{l}\text { Pretreated } \\
\text { with tolbutamide } \\
\text { for } 7 \text { days }\end{array}$ & 0.6020 & 0.0422 & 0.0764 & 0.7206 \\
\hline
\end{tabular}

Each value represents the mean of two experiments.

The percent of each metabolite is given in terms of CHS-Na equivalent.

the amount of substrate: CHS-Na $(100 \mathrm{mg})$

the dose of tolbutamide: $120 \mathrm{mg}$ per $\mathrm{kg}$ body wt. daily

amide, whereas almost no change occurred in the metabolism of cyclohexanol when pretreated with tolbutamide. Also, as shown in Table II, the influences of tolbutamide on the metabolism of cyclohexylamine, cyclohexanone, and cyclohexanol in rabbit liver homogenate were almost the same as those in the in vivo experiment described above. These results suggest that tolbutamide highly intensifies the activity of liver enzymes which oxidize cyclohexylamine to such an extent that the cleavage of cyclohexane ring follows.

Accordingly, it may be concluded that the metabolism of CHS-Na is accelerated by phenylbutazone, phenobarbital, and tolbutamide in the rabbit.

$\left[\begin{array}{l}\text { Chem. Pharm. Bull. } \\ \text { 20(1) } 180-184(1972)\end{array}\right]$

UDC $547.783 .09: 577.15 .04$

\title{
Effect of Diphenylhydantoin on the Drug Metabolism and the Fatty Acid Composition of Phospholipids in Hepatic Microsomes ${ }^{1)}$
}

\author{
Toshiniko Ariyoshi and Eigo Takabatake
}

Faculty of Pharmaceutical Sciences, Nagasaki University ${ }^{2}$

(Received May 15, 1971)

Drug metabolizing enzymes of hepatic microsomes are induced by various chemicals which are roughly classified into two types, a representative of one group is phenobarbital $(\mathrm{PB})$ and another is 3 -methylcholanthrene $(\mathrm{MC}){ }^{3}{ }^{3}$ ) There are some differences between these two types in the activation of drug metabolizing enzymes and in the influence on microsomal cytochromes.

We found that ethanol and/or ethionine enhanced apparent aniline hydroxylase activity and pointed out the difference between $\mathrm{PB}$ and ethanol and/or ethionine in the effects on microsomal phospholipids. ${ }^{4,5)}$

1) This work was presented at the 91st Annual Meeting of Pharmaceutical Society of Japan, Fukuoka, April 1971.

2) Location: Bunkyo-machi, Nagasaki.

3) A.H. Conney, Pharmacol. Rev., 19, 317 (1967).

4) T. Ariyoshi and E. Takabatake, Life Sci., 9, Part II, 371 (1970).

5) T. Ariyoshi and E. Takabatake, Chem. Pharm. Bull. (Tokyo), 20, 170 (1972). 
Eling, et al. ${ }^{6)}$ recently reported that diphenylhydantoin (DPH) is also an inducer resembling to more $\mathrm{PB}$ than MC. On the other hand, Ariyoshi and Remmer ${ }^{7)}$ observed that, in rats with ethanol-induced fatty livers maintaining on either normal or choline deficient diet, the content of triglyceride was decreased by DPH but, in contrast, increased by $\mathrm{PB}$ treatment. Therefore, it was attempted to compare the effect of DPH on both drug- and lipid-metabolism in liver with that of PB.

\section{Material and Method}

Female Wistar rats weighing $90-120 \mathrm{~g}$ were used and they fed Clea rat chow for one week prior to experiments. DPH and PB was injected intraperitoneally at a dose of $80 \mathrm{mg} / 2 \mathrm{ml} / \mathrm{kg}$ once daily for 5 days and 3 days, respectively. The animals were sacrificed $24 \mathrm{hrs}$ after last injection.

The estimation of aniline or aminopyrine metabolizing enzyme activities and cytochromes of hepatic microsomes were carried out by the procedures described previously. ${ }^{8}$ ) Microsomal lipids were isolated by the method of Folch, et al.9) The phospholipids were separated from the lipid mixture by silicic acid chromatography. ${ }^{10}$ The fatty acid composition of each phospholipid was determined by gas chromatography.5) Statistical analysis were calculated by the method of $t$-test.

TABle I. Diphenylhydantoin Effects on the Hepatic Constituents, Drug Metabolizing Activities and Microsomal Cytochromes

(A) Hepatic constituents

\begin{tabular}{lccc}
\hline & Control & Diphenylhydantoin & Phenobarbital \\
\hline body weigt $(\mathrm{g})$ & $107 \pm 6(9)$ & $104 \pm 4(11)$ & $105 \pm 8(8)$ \\
liver weight $(\mathrm{g})$ & $5.7 \pm 0.4$ & $5.3 \pm 0.3$ & $6.4 \pm 0.7$ \\
$\quad$ (g/100 g b.w.) & $5.3 \pm 0.2$ & $5.1 \pm 0.2$ & $6.1 \pm 0.2^{b, c)}$ \\
Triglyceride $(\mathrm{mg} / \mathrm{g})$ & $4.9 \pm 0.4$ & $5.3 \pm 0.8$ & $8.5 \pm 0.8^{b, c)}$ \\
Microsomal & & & \\
$\quad$ Protein $(\mathrm{mg} / \mathrm{g})$ & $15.2 \pm 0.3$ & $15.4 \pm 0.4$ & $\left.20.7 \pm 1.1^{b, d}\right)$ \\
Cholesterol $(\mu \mathrm{g} / \mathrm{g})$ & $338 \pm 6$ & $352 \pm 8$ & $362 \pm 14$ \\
Phosphrous of & & & \\
Phospholipid $(\mu \mathrm{g} / \mathrm{g})$ & $208.9 \pm 2.9$ & $218.5 \pm 2.6$ & $273.4 \pm 9.5^{b, c)}$
\end{tabular}

(B) Drug metabolizing enzyme activities and microsomal cytochromes

\begin{tabular}{|c|c|c|c|}
\hline & Control & Diphenylhydantoin & Phenobarbital \\
\hline \multicolumn{4}{|l|}{$\begin{array}{l}\text { Enzyme activity } \\
\quad(\mathrm{m} \mu \mathrm{mole} / \mathrm{mg} \text { prot } / \mathrm{min})\end{array}$} \\
\hline Aniline hydroxylase & $0.66 \pm 0.01$ & $0.62 \pm 0.01$ & $0.73 \pm 0.03^{c)}$ \\
\hline Aminopyrine demethylase & $6.03 \pm 0.30$ & $7.44 \pm 0.34^{a)}$ & $10.66 \pm 0.72^{b)}$ \\
\hline \multicolumn{4}{|l|}{$\begin{array}{l}\text { Cytochrome } \\
\text { (absorbance } \cdot 10^{-3} / \mathrm{mg} \text { prot) }\end{array}$} \\
\hline $\begin{array}{l}\mathrm{b}_{5} \\
\mathrm{P}-450\end{array}$ & $\begin{array}{l}44.2 \pm 2.2 \\
33.3 \pm 2.0\end{array}$ & $\begin{array}{l}48.0 \pm 1.3 \\
36.0 \pm 0.6\end{array}$ & $\begin{array}{l}51.6 \pm 2.9^{a)} \\
67.0 \pm 2.2^{b, d)}\end{array}$ \\
\hline \multicolumn{4}{|l|}{$\begin{array}{l}\text { Spectral change } \\
\text { (absorbance } \cdot 10^{-3} / \mathrm{mg} \text { prot) }\end{array}$} \\
\hline Aniline & $18.8 \pm 0.4$ & $22.3 \pm 0.8^{a)}$ & $38.5 \pm 1.5^{b, d)}$ \\
\hline Hexobarbital & $7.5 \pm 0.6$ & $8.9 \pm 1.0$ & $17.0 \pm 1.2^{b, d)}$ \\
\hline
\end{tabular}

Diphenylhydantoin and phenobarbital was injected intraperitoneally at a dose of $80 \mathrm{mg} / \mathrm{kg}$ once daily for 5 days and 3 days, respectively. The animals were sacrificed $24 \mathrm{hrs}$ after last injection, and the number of rats is shown in parentheses. All values are mean \pm standard error.

a); $p<0.05\}$ significantly different from control to dipehenylhydantoin or phenobarbital

b): $p<0.01\}$

$\left.\begin{array}{l}\text { c) }: p<0.05 \\ d): p<0.01\end{array}\right\}$ significantly different from diphenylhydantoin to phenobarbital

6) T.E. Eling, R.D. Harbison, B.A. Becker and J.R. Fouts, J. Pharmacol. Exptl. Therap., 171, 127 (1970).

7) T. Ariyoshi and H. Remmer, Arch. Exptl. Pathol. Pharmakol., 260, 90 (1968).

8) T. Ariyoshi, E. Takabatake and H. Remmer, Life Sci., 9, Part II, 361 (1970).

9) J.F. Folch, M. Lee and G.H. Sloane-Stanley, J. Biol. Chem., 226, 497 (1957).

10) D.J. Hanahan, J.C. Dittmer and E.A. Warashina, J. Biol. Chem., 228, 685 (1957); R.J. Morin, Cancer Res., 25, 118 (1965). 


\section{Result}

As shown in Table I, DPH at the dose used did not affect liver weight, triglyceride content, microsomal protein and phospholipid content, while PB increased significantly these parameters. DPH enhanced aminopyrine demethylase activity and the spectral change with aniline, but $\mathrm{PB}$ increased not only aminopyrine demethylase but also aniline hydroxylase and microsomal cytochromes.

$\mathrm{PB}$ increased the total phospholipid content with the increase of phosphatidylethanolamine (PE) and phosphatidylcholine (PC) fraction. However, as shown in Table II, DPH increased only $\mathrm{PE}$ fraction. Thus, the percentage composition of microsomal phospholipids was remained unchanged by $\mathrm{PB}$ but changed by $\mathrm{DPH}$ increasing the percentage of $\mathrm{PE}$.

TABLE II. Diphenylhydantoin Effect on Composition of Hepatic Microsomal Phospholipids

(A) Phosphorus content, $\mu \mathrm{g} / \mathrm{g}$ of liver

\begin{tabular}{cccc}
\hline \hline Fraction $^{a)}$ & Control & Diphenylhydantoin & Phenobarbital \\
\hline PE & $62.0 \pm 1.1$ & $76.2 \pm 1.9^{c)}$ & $89.6 \pm 3.1^{c, d)}$ \\
S & $15.2 \pm 2.3$ & $12.4 \pm 1.6$ & $17.6 \pm 2.3$ \\
PC & $116.8 \pm 2.1$ & $116.7 \pm 2.4$ & $151.5 \pm 5.7^{c)}$ \\
PI & $14.9 \pm 2.7$ & $13.2 \pm 0.4$ & $14.6 \pm 1.5$ \\
Total & $208.9 \pm 2.9$ & $218.5 \pm 2.6$ & $273.4 \pm 9.5^{c, d)}$ \\
\hline
\end{tabular}

(B) Per cent phosphorus of total phosphorus

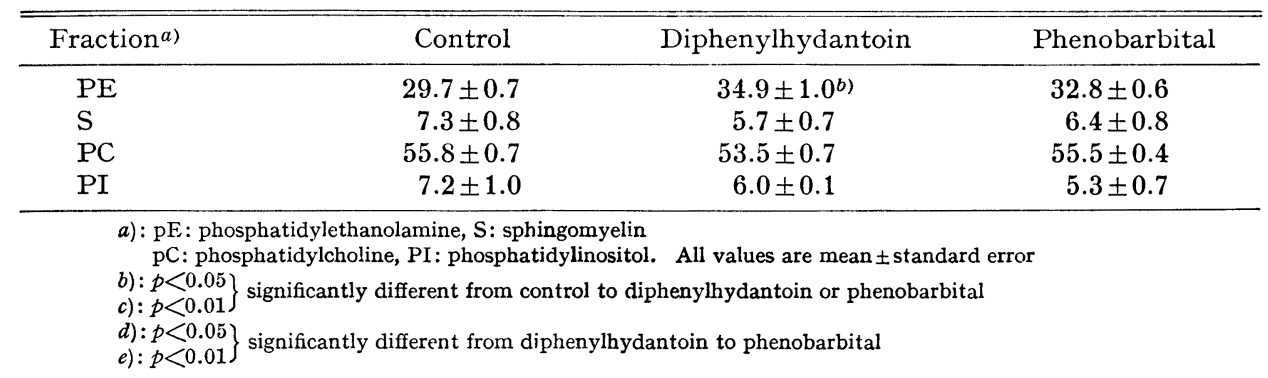

The effect of $\mathrm{DPH}$ and $\mathrm{PB}$ on the fatty acid composition of each phospholipid fraction were summarized in Table III. The major fatty acids were 16:0, 18:0, 18:1, 18:2, 20:4 and 22:6. In PE fraction, stearic acid was increased by DPH but decreased by PB. On the contrary, the unsaturated fatty acids were increased by PB but decreased by DPH. In PC fraction, the unsaturated fatty acids were also decreased significantly by DPH but not affected by $\mathrm{PB}$.

TABLE III. Diphenylhydantion Effect on Fatty Acid Composition of Hepatic Microsomal Phospholipids

(A) Phosphatidylethanolamine

\begin{tabular}{crcc}
\hline Fatty acids & Control & Diphenylhydantoin & Phenobarbital \\
\hline $16: 0$ & $22.3 \pm 0.9$ & $24.0 \pm 0.4$ & $18.6 \pm 1.2^{b, e)}$ \\
$16: 1$ & $1.1 \pm 0.2$ & $0.6 \pm 0.1$ & $0.8 \pm 0.1$ \\
$18: 0$ & $32.0 \pm 0.3$ & $34.0 \pm 0.3^{b)}$ & $27.0 \pm 0.7^{c, e)}$ \\
$18: 1$ & $14.6 \pm 0.5$ & $15.1 \pm 0.3$ & $15.8 \pm 0.3$ \\
$18: 2$ & $6.0 \pm 0.7$ & $5.5 \pm 0.6$ & $6.9 \pm 0.3$ \\
$20: 4$ & $15.2 \pm 0.8$ & $13.6 \pm 0.5$ & $18.9 \pm 0.7^{c, e)}$ \\
$22: 6$ & $8.9 \pm 0.2$ & $7.3 \pm 0.4^{b)}$ & $12.4 \pm 1.3^{b, e)}$ \\
Unsaturated fatty acids & $45.8 \pm 0.9$ & $42.0 \pm 0.6^{c)}$ & $54.8 \pm 1.6^{c, e)}$ \\
\hline
\end{tabular}


(B) Sphingomyelin

\begin{tabular}{crcc}
\hline Fatty acids & Control & Diphenylhydantoin & Phenobarbital \\
\hline $16: 0$ & $31.4 \pm 0.6$ & $33.3 \pm 0.9$ & $\left.22.6 \pm 0.4^{b, d}\right)$ \\
$18: 0$ & $32.4 \pm 1.2$ & $37.5 \pm 0.7^{b)}$ & $46.3 \pm 0.9^{c, d)}$ \\
$18: 1$ & $8.6 \pm 1.3$ & $10.1 \pm 1.1$ & $8.2 \pm 0.8$ \\
$18: 2$ & $3.1 \pm 0.3$ & $1.7 \pm 0.4$ & $2.6 \pm 0.1$ \\
$20: 4$ & $4.4 \pm 1.0$ & $2.8 \pm 0.5$ & $4.0 \pm 0.1$ \\
()$\left.^{a}\right)$ & $5.2 \pm 0.8$ & $4.1 \pm 0.8$ & $2.2 \pm 0.5$ \\
$22: 6$ & $14.1 \pm 1.2$ & $10.9 \pm 2.2$ & $13.7 \pm 0.1$ \\
\hline
\end{tabular}

(C) Phosphatidylcholine

\begin{tabular}{crcc}
\hline Fatty acids & Control & Diphenylhydantoin & Phenobarbital \\
\hline $16: 0$ & $21.0 \pm 0.5$ & $23.2 \pm 0.9$ & $\left.18.1 \pm 0.9^{b, e}\right)$ \\
$16: 1$ & $0.9 \pm 0.1$ & $0.4 \pm 0.1$ & $0.9 \pm 0.1$ \\
$18: 0$ & $25.2 \pm 0.9$ & $27.5 \pm 0.9$ & $26.9 \pm 0.9$ \\
$18: 1$ & $13.2 \pm 0.2$ & $13.4 \pm 0.6$ & $12.5 \pm 0.9$ \\
$18: 2$ & $14.6 \pm 0.3$ & $12.7 \pm 0.5^{b)}$ & $15.3 \pm 0.7^{d)}$ \\
$20: 4$ & $16.9 \pm 0.4$ & $16.4 \pm 0.3$ & $18.1 \pm 1.2$ \\
$22: 6$ & $7.4 \pm 0.2$ & $6.3 \pm 0.2^{b)}$ & $7.7 \pm 0.5^{d)}$ \\
Unsaturated fatty acids & $53.5+0.5$ & $49.2+0.4^{c)}$ & $54.5+0.5^{e)}$ \\
\hline (D) Phosphatidylinositol & & & \\
\hline \hline Fatty acids & & & \\
\hline $16: 0$ & Control & Diphenylhydantoin & Phenobarbital \\
$18: 0$ & $31.0 \pm 1.5$ & $27.7 \pm 2.4$ & $25.5 \pm 0.4$ \\
$18: 1$ & $43.4 \pm 0.5$ & $48.0 \pm 2.2$ & $44.6 \pm 1.3$ \\
$18: 2$ & $7.3 \pm 0.7$ & $9.2 \pm 0.2$ & $3.4 \pm 0.2$ \\
$20: 4$ & $3.0 \pm 0.2$ & $2.4 \pm 0.4$ & $7.9 \pm 1.0$ \\
$22: 6$ & $6.3 \pm 0.8$ & $7.8 \pm 0.2$ & $10.9 \pm 0.5$ \\
\hline
\end{tabular}

a): unidentified. All values are mean \pm standard error, and expressed as percentage of total fatty acids detected.

$\left.\begin{array}{l}\text { b) }: p<0.05 \\ c): p<0.01\end{array}\right\}$ significantly different from control to diphenyihydantoin or phenobarbital

$\left.\begin{array}{l}d): p<0.05 \\ e): p<0.01\end{array}\right\}$ significantly different from diphenylhydantoin to phenobarbital

\section{Discussion}

It has been known that DPH stimulated not only its own metabolism ${ }^{11)}$ but also shortened hexobarbital-12) or meprobamate-13) induced sleeping time and zoxazolamine-13) induced paralysis time probably being due to the acceleration of metabolism of these drugs. The dose of DPH used those experiments was 40,100 and $120 \mathrm{mg} / \mathrm{kg}$, respectively. Previous experiments ${ }^{14}$ ) indicated that higher dose of $\mathrm{DPH}$ than $80 \mathrm{mg} / \mathrm{kg}$ showed the acute toxicity such as ataxia and paralysis but prolonged treatment with lower dose, $30 \mathrm{mg} / \mathrm{kg}$ of DPH for 20 days affected neither aminopyrine demethylase activity nor cytochrome $b_{5}$ and P-450 contents. In the present study, therefore, $80 \mathrm{mg} / \mathrm{kg}$ of $\mathrm{DPH}$ was administered for 5 days as dosage without causing any toxic effect. DPH at this dose enhanced aminopyrine de-

11) N. Gerber and K. Arnold, J. Pharmacol. Exptl. Therap., 164, 232 (1968).

12) H. Remmer, "Drug Tolerance," in Symposium Enzymes and Drug Action, Ciba Found., 1962, p. 276.

13) R. Kato and P. Vassanelli, Biochem. Pharmacol., 11, 779 (1962).

14) T. Ariyoshi and H. Remmer, unpublished data. 
methylase activity but did not affect aniline hydroxylase or microsomal protein and cytochrome $b_{5}$ and P-450. This observation agreed with that of Eling, et al. ${ }^{6)}$ except they stated that DPH, $75 \mathrm{mg} / \mathrm{kg}$ injected intraperitoneally twice a day for 3 days, increased P-450 content. DPH did not increase the spectral change of P-450 with hexobarbital, a type I substrate, but increased significantly the $\mathrm{N}$-demethylation of aminopyrine, also a type I substrate. The spectral change with aniline was increased by DPH but the hydroxylation of aniline was not enhanced. These facts are not interpreted only by the higher affinity of aniline $\left(\mathrm{Km}=10^{-5} \mathrm{M}\right)$ than that of aminopyrine $\left(\mathrm{Km}=10^{-4} \mathrm{M}\right) \cdot{ }^{8,15}$ ) Some other factors must be taken into consideration.

The effect of DPH on the microsomal phospholipid content and on their fatty acid compositions differes markedly from those of $\mathrm{PB}$ or ethanol and/or ethionine. $\mathrm{PB}$ increased the total phospholipid content being due to the increase of PE and PC, but DPH increased significantly only PE content and resemble to ethanol and/or ethionine. However, ethanol or ethionine enhanced only apparent aniline hydroxylase activity and increased the percentage of polyunsaturated fatty acids in PE fraction.,5) On the contrary, DPH enhanced only aminopyrine demethylase activity and decreased the percentage of unsaturated fatty acids in PE or PC fraction. Minor phospholipids, such as sphingomyelin and phosphatidylinositol, seemed not to be so much affected by these agents.

The important roles of phospholipids in the hepatic microsomal oxidation have been ascertained by several investigators, Strobel, et al.,16) Chaplin, et al..17) It is not obvious how the changes in the composition of phospholipids in microsomes relate to the drug metabolism, but DPH might change the conformation and function of endoplasmic reticulum and alter apparent enzymatic activity.

15) H. Remmer, R.W. Estabrook, J. Schenkman and H. Greim, Arch. Exptl. Pathol. Pharmakol., 259, 98 (1968).

16) H.W. Strobel, A.Y.H. Lu, J. Heidema and M.J. Coon, J. Biol. Chem., 245, 4851 (1970).

17) M.D. Chaplin and G.J. Mannering, Mol. Pharmacol., 6, 631 (1970).

[Chem. Pharm. Bull.

20( 1 ) $184-187(1972)$

UDC 547.853 .02 .03

\title{
Conformational Analysis of 1,3-Diethyl-5-methyl-5-nitrohexahydropyrimidine
}

\author{
Tadakazu Tsuji ${ }^{1 a}$ and Yoshinisa OKamoto ${ }^{1 b)}$ \\ Department of Chemistry, Japan Women's University ${ }^{1 a}$ ) and College of \\ Pharmaceutical Science, Kitasato University ${ }^{\mathbf{1 b})}$
}

(Received May 19, 1971)

Two research groups ${ }^{2,3)}$ have determined activation energies for the ring inversion of simple hexahydropyrimidines by the nuclear magnetic resonance (NMR) studies at lowtemperature. Before those works, Urbanski and his co-workers ${ }^{4}$ ) have investigated some 5-methyl-5-nitrohexahydropyrimidines and tentatively concluded that the 1,3-diequatorial

1) Location: a) Mejirodai, Bunkyo-ku, Tokyo; b) Shirogane, Minato-ku, Tokyo.

2) F.G. Riddel and J.M. Lehn, Chem. Commun.,1966, 375; F.G. Riddel, J. Chem. Soc. (B), $1967,560$.

3) R.F. Farmer and J. Hamer, Tetrahedron, 24, 829 (1968).

4) H. Piotrowska and T. Urbanski, J. Chem. Soc., 1962, 1942; D. Gürne, T. Urbanski, M. Witanowski, and L. Stefaniak, Tetrahedron, 20, Suppl., 195 (1964). 